RESPONSE TO DEGRAVELLES

Invited Contribution

\title{
Of Grass and Hammers: Transgressive Readings in Curriculum
}

PHIL BAYLISS

University of Exeter (UK)

DeGravelles explores the writing of Walt Whitman's Leaves of Grass and a novel by Michael Cunningham (Specimen Days) for an "examination of the intersections of literature, chaos theory and curriculum"(p. 47). There are echoes of layers in both the writings of Cunningham, and Whitman, and of deGravelles' interpretation itself, that reward the recursiveness of reading. The "non-linear recursive practices" inherent in deGravelles own writing allow for an interative reading of "curriculum" as a concept and I am grateful for a chance to allow my thoughts to wander across the sense of "strangeness," which leads to unpredictability and relationships in considering the curriculum as something which, following Whitman, is growing and alive. If deGravelles follows Whitman's lead in developing a critique of "singular and fixed knowledge" (p. 49), then understanding complexity can further support deGravelles' contention that curriculum can be understood as connection and relationship, rather than "thing" (p. 52).

DeGravelles cites aspects of the Whitman poetics and their extension in Cunningham and demonstrates the emergent meanings and their impact on "learners" in different ways. The iteration of text is chaotic and allows for transgressive meanings to emerge, which

raise at times unsettling questions about what it is to live with poetry, and presenting interpretations that far exceed the boundaries of traditional or school based (curriculum). (DeGravelles, p. 50 - my change to "curriculum") 
This use of Whitman, and indeed Whitman's poetry itself, is resonant with a Kristevan poetics:

Only in poetic language is found the practical realization of the "totality" (though we prefer the term "infinity") of the code at man"s (sic) disposition. In this perspective, literary practice is revealed to be the discovery and the explorations of the possibilities of language; an activity that frees man from certain linguistic (psychical, social) networks; a dynamism that breaks the inertia of language-habits and offers the linguist a unique opportunity to study the becoming of the signification of signs (signifiance). (Kristeva, 1998, p. 28)

If we are concerned, through adopting a chaotic poetics, to breakout from certain linguistic networks, then deGravelles seeks to develop a concept of "curriculum"1 A traditional view of a concept is that of the relationship between a signifier and that which it signifies. Frege understands a "word" as having denotative ("“Bedeutung" or content) and connotative ("Sinn" or expression) meanings and the logic of the word is in its denotation whilst its connotative meaning is located in the way the word is used (see Zalta, 2009).

Thus, curriculum in its denotative aspect, refers to an "object-in-the-world," a "thing" which exists (in some sense of exists). A curriculum is analogous to a tool that has use and purpose. It could also be said to be teleological, that is, its design determines the ways that the tool can be used.

Tools can be badly designed and, as Mark Twain said, if you only have a hammer, then every problem looks like a nail.

"Curriculum" here has aims, goals, objectives/targets. The design of the tool is linear and what Deleuze and Guattari call the "arborescent."

The arborescent form admits typological explanations. In a hierarchical system, an individual has only one active neighbor, his or her hierarchical superior. The channels of transmission are pre-established: the arborescent system preexists the individual, who is integrated into it at an allotted space (signifiance and subjectification). (Deleuze \& Guattari, 1987, p. 16)

Here, in this way of thinking, the purpose (aim) of the curriculum, created through intelligent design, is external to the process of teaching and learning and conforms to an Enlightenment tradition of producing autonomous individuals, through supporting linear trajectories of development, where learners are seen as "perfectable." The Globalization project (Tikly, 2001) of economic and material well-being through "Education for All" (UNESCO, 1990) also acts teleologically-outcomes based performance management acts as negative feedback to constrain the system to produce those, and only those, effects for which the curriculum was designed.

\footnotetext{
${ }^{1}$ Curriculum is a concept. It could be argued that the purpose of philosophy is to create concepts. Concepts, following Deleuze and Guattari $(1994$, p. 17) "are created as a function of problems which are thought to be badly understood of badly posed (pedagogy of the concept)".
} 
If we understand the concept of curriculum as a simple relationship between content and expression, then this can be seen as a discursive practice, which objectifies learning and subjects learners to programmes and regimes (Foucault, 1980), to create docile bodies.

The arborescent renders abstract a knowledge to be assimilated (acquired) or constructed (Sfard, 1998). The content/expression is inscribed on the body of the learner, through the agency of the teacher. Teachers teach and learners learn. The socio-cultural theory of Vygotsky (see Wertsch, 1988) uses the metaphor of scaffolding to suggest a mechanistic "building of knowledge," where the expert inducts the novice into an existing practice, or existing body of knowledge-the knowledge/practice is not a coconstruction (Bayliss \& Dillon, forthcoming; Dillon et al., forthcoming,). The relationship between teacher and learner is arborescent, based on asymmetric power structures.

An assumed Newtonian relationship between teaching and learning is represented in Figure 1. In a linear mode, what is the resultant of teaching and learning? Knowledge?

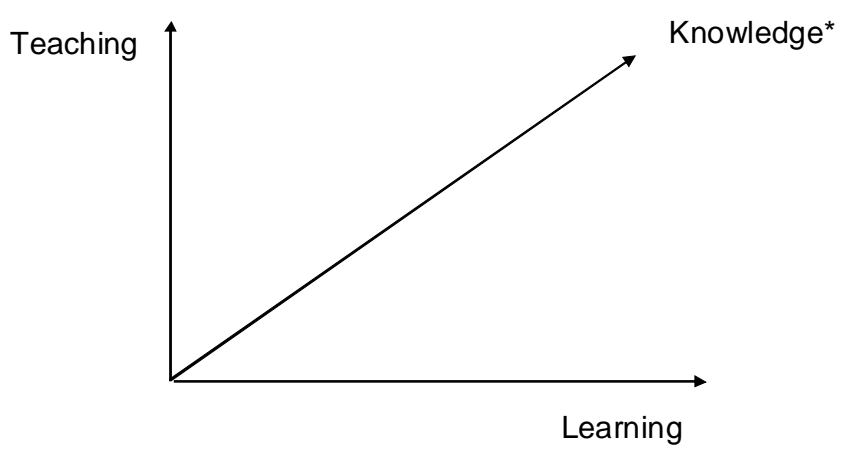

Figure 1. Teaching and learning: Fixed attractors and linear representation

This diagram assumes an equilibrium or steady state which corresponds to the fixed attractors of teaching and learning (see Coveney \& Highfield, 1995, p. 424 for the different understandings of attractors). But teaching and learning are not fixed point variables; they are activities or actions, which in themselves assume a multiplicity, not a singularity. This diagram is therefore misleading, but is a comfortable fiction from which the idea of a "steady progress in learning," or of "teaching and learning styles" can be derived. Once the concept of teaching or of learning assumes the status of a linguistic expression,

(the) form of expression (itself) becomes linguistic rather than genetic: in other words, it operates with symbols that are comprehensible, transmittable and modifiable from outside. (Deleuze \& Guattari, 1987, p. 60)

Further, this very simple system is not bounded in any way-it acts as an "abstract machine" (Deleuze \& Guattari, 1987) which, though purporting to represent something "alive," through its abstraction produces something which is sterile or dead. 
Certainly such a representation does not assume a change in the nature of the participants in the process of teaching and learning. If we cast Figure 1 into a Cartesian Dualism, then outcomes (the resultant designated in Figure 1) are concerned with either the mind or the body, but not their interrelationship and co-dependency. This simple linear dynamics allows knowledge to be predictable.

If we reconfigure Figure 1 as a dynamic system where teaching and "learning are not variables, but can be seen as limit-cycle attractors then something different occurs, as in Figure 2.

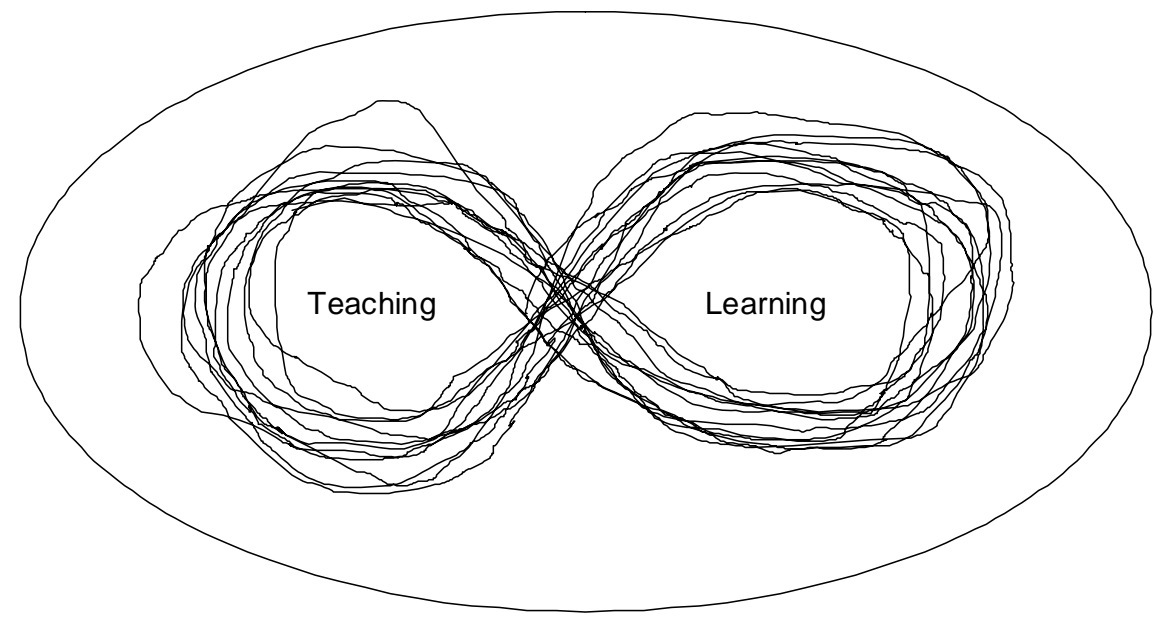

Figure 2. Teaching and learning: limit-cycle attractors and dynamic approaches

This diagram assumes a periodic state constrained by the limit-cycle attractors of teaching and learning. This appears to conform to the socio-cultural theoretical position of scaffolding, where the influence of the teacher acts as a limit-cycle attractor, constraining what is to be known, or learnt. In this Figure, I have added the boundary (membrane) that defines a system.

The direction the system (organism) will travel, or the emergent property of the system may be seen as knowledge, in that given the cultural context in which such a system is located, the foundation of the system is to promote learning. The construction of knowledge through limit-cycle attractors (scaffolding) is defined through the nature of the limits. The limit-cycle attractors define the nature of the learning itself; the social nature of the limits define both the "value" (what is good) and the content of learning (what is to be learnt).

If we add further dimensions (attractors) to the system (Figure 3), we increase complexity in the system. 


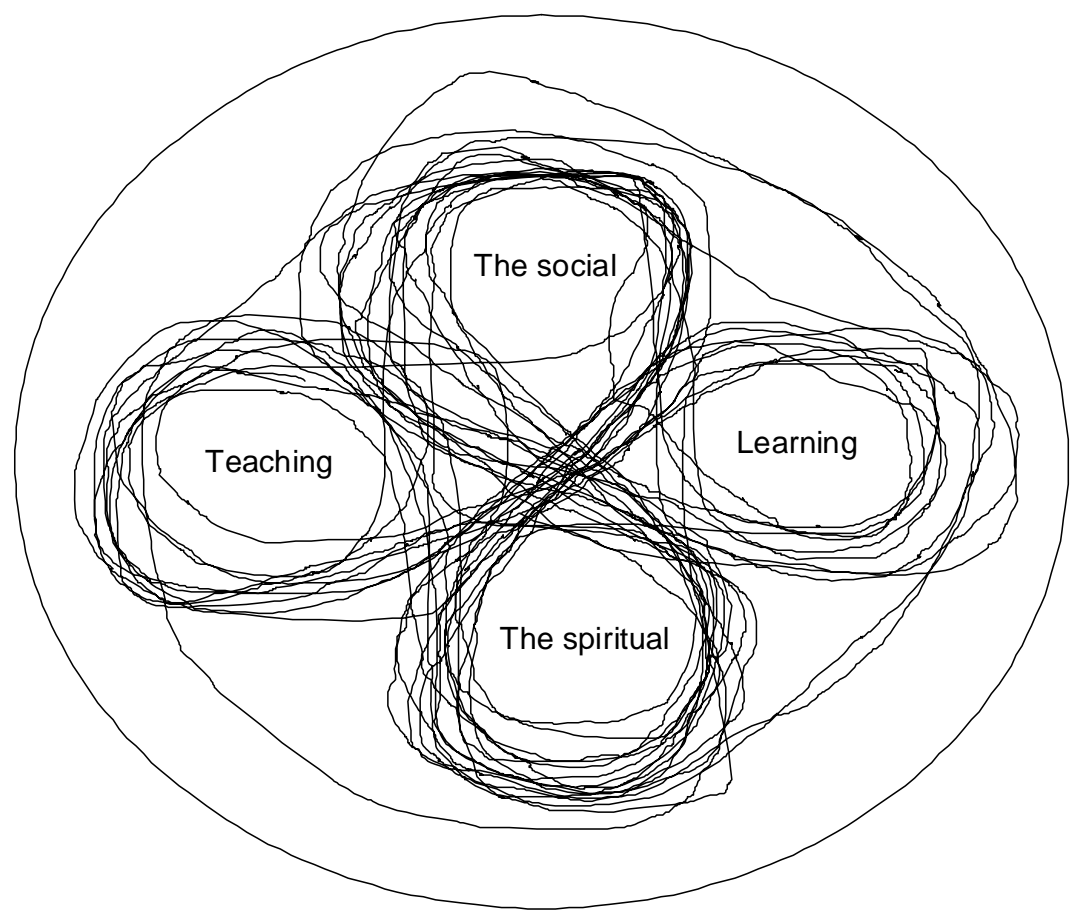

Figure 3. Strange Attractors and the multiplicities of "learning"

In this Figure the system becomes chaotic and the "multiplicities" act as strange attractors. If the curriculum is alive (following Whitman/deGravelles), the biological metaphor requires a boundary (skin) between the organism and it environment. If the system is, in itself, a multiplicity, then it takes on the form of a rhizome: grass propagates rhizomatically.

A rhizome ceaselessly establishes connections between semiotic chains, organizations of power and circumstances relative to the arts, sciences and social struggles. A semiotic chain is like a tuber agglomerating very diverse acts, not only linguistic, but also perceptive, mimetic, gestural, cognitive: there is no language in itself, not are there any linguistic universals, only a throng of dialects, patois, slangs and specialized languages. There is no ideal speaker-listener, any more than there is an homogeneous linguistic community. (Deleuze \& Guattari, 1987, p. 7)

The emergent properties of the system are not predictable from the activities of the multiplicities inherent in the system, they also change the nature of the system itself (i.e., the organism changes the nature of the environment, with which it is interdependent and co-constitutional. For deGravelles, the iterations within Cunningham's novel change the ground of the curriculum and this change of ground changes the socio-historical environment (from old New York, to post 9/11 New York to New York as theme park).

Here the processes of teaching and learning become multi-dimensional. The strange attractors, as they relate to human agency, corporeality, embodiment of mind and the landscape of the social, appear to me to suggest a complexity which goes beyond a simple idea of "learning." 
What emerges? In English, we have no words for this, or at least the denotation of education or instruction have lost this complexity and become "order-words":

Language is not to be believed but to be obeyed, and to compel obedience" (....). Language is neither informational nor communicative. It is not the communication of information but something quite different: the transmission of order-words, either from one statement to another or within each statement, insofar as each statement accomplishes an act and the act is accomplished in the statement. (Deleuze and Gauattari, 1987: 75)

Education and Instruction are nominalizations, derived from verb structures. In other languages, words translated as "education" are not nominalizations, but are expressed as actions: "curriculum" is enacted.

"Khumuunjilech," a Mongolian word, is a causative verb: "to cause to become human" (Bayliss, forthcoming); "Oosimich," a First Nations Nutka word from Vancouver Island, Canada is a spiritual methodology of knowledge acquisition, where the source of success is to be found in the spiritual realm (Atleo, 2004, p. 84). Atleo presents a theory of "heshook-ish tsawalk" (everything is one), which is predicated by a "worldview wherein the universe is regarded as a network of relationships" (p. 118). The last has resonance with Tibetan Buddhist thought which sees the "acquiring of wisdom" as an outcome of the interrelationship between the "Geshwe" (teacher, guru, spiritual leader), their novices (Levitt, 1999) and the beliefs of the Tibetan Buddhist spiritual system.

If the state of the organism/system in Figure 3 is seen as a series of phase states, how can this be described? "To become human"? "To become one"? "To achieve wisdom"?

These enactives change the ontology of "teacher," "learner," and "curriculum." The emergent properties of the system also change the nature of the environment in which the system is grounded. The attractors in Figure 3 are indicative. Atleo (2004) notes that "generosity" is prized in Nutka society; while engagement with the ancestors, or the animist deities of the $4^{\text {th }}$ World $^{2}$ is commonplace. This also has resonances with Cunningham's "voice in the machine," which yields "unexpected meanings and results."

If we reject dualistic approaches within assumed linearities, then deGravelles points the way of understanding curriculum as a process of co-constituting both teacher and learner, which has the potential to transform both the teacher and the learner, as well as the "ground" or environment (Luhmann, 1995).

In using Whitman as a "curriculum," deGravelles opens up the possibility of conceptualizing "curriculum" not as a linear, arborescent (teleological) tool, but as a foregrounded element of a rhizomatically semiotic or semantic field (network), which is chaotic.

Here, signifiance (Kristeva, 1998) does not confine itself to a linear relationship between a signifier and its signified; instead it is concerned with how signs come in to being and how they can be transformed. This allows "curriculum" to be understood as a

\footnotetext{
${ }^{2}$ The Fourth World - the world that exist above the Arctic Circle and comprises predominantly of nomadic people: The Nutka of Vancouver, the Saamii of Scandanavia, The Yakut and Buryat people of Siberia. See Pentikainen, 2006.
} 
chaotic or complex system, which does not act teleologically. Instead "curriculum" is immanent to the system and whatever "outcomes" are, they are emergent not determined. A poetics of curriculum, explored by deGravelles, allows for curriculum to be thought of not "as an act of closure, but an explosion of meanings" (p. 55). Such an explosion offers the potential for transformative practices, which, I would argue are sorely needed within education generally, not just in the reading curriculum. Grass not hammers.

\section{References}

Atleo, R. 2004 Tsawalk: a Nuu-chah-nulth worldview. Vancouver: UBC press.

Bayliss (forthcoming) Mongolian education in a time of change: cosmologies, history and cultural formations. Journal of Mongol Studies.

Bayliss, P. \& Dillon. P. 2009. Cosmologies and lifestyles: a cultural ecological framework and its implications for education systems. Paper to be presented at ISATT, Rovaniemi, July, 2009.

Coveney, P. \& Highfield, R. 1995. Frontiers of complexity. London: Faber and Faber.

Deleuze, Gilles \& Felix Guattari. 1987. A thousand plateaus. Minneapolis: University of Minneapolis Press.

Dillon, P., Bayliss, P., Stolpe, I. \& Bayliss, L. (forthcoming) What constitutes "context" in sociocultural research? How the Mongolian experience challenges theory. Transtext(e)s Transcultures: Journal of Global Cultural Studies.

Foucault, M. 1980. "Body/power" and "Truth and power" in Colin Gordon (editor) Michel Foucault: Power/knowledge, Harlow, Essex: Harvester Press.

Kristeva, J. 1998. Towards a semiology of paragrams in Patrick French and Roland Francois Lack (eds) The Tel Quel reader. London: Routledge.

Levitt, H. 1999. The development of wisdom: an analysis of Tibetan Buddhist experience. Journal of Humanistic Psychology, 39(2): 86-105

Luhmann, N. 1995. Social systems. Stanford, Calif: Stanford California Press.

Pentakainen, J. 2006. Shamanism and culture. Helsinki: ETNIKA CO.

Sfard, A. 1998. On two metaphors for learning and the dangers of choosing just one. Educational Researcher, 27( 2): 4-13.

Tikly, L. 2001. Globalisation and education in the postcolonial world: towards a conceptual framework. Comparative Education, 37(2): 151-171

UNESCO. 1990. Education for all. Geneva: UNESCO.

Wertsch, J. 1988. Vygotsky and the social formation of mind. Harvard: Harvard University Press.

Zalta, E. N. 2009. "Gottlob Frege", The Stanford Encyclopedia of Philosophy (Summer 2009 Edition), Edward N. Zalta(ed.), URL: http://plato.stanford.edu/archives/sum2009/entries/frege/. Downloaded, June, 2009.

\section{About the author}

Phil Bayliss gained his PhD in Linguistics and Education (Discourse Analysis and Integration) and has spent his academic life following strands of disability, inclusion and discourse. In recent times he has been involved with complexity, chaos and social systems as these relate to post-structural concepts of "Other" (particularly in the field of Disability Studies and further cultural studies). He is a Senior Lecturer in Special Education,. Disability and Inclusion at the University of Exeter and is the Programme Director for the Masters in Disability and Inclusion. He has a spent a lot of time in Mongolia, which changes the way you see the world. 
PHIL BAYLISS

(C) Copyright 2009. The author, PHIL BAYLISS assigns to the University of Alberta and other educational and non-profit institutions a non-exclusive license to use this document for personal use and in courses of instruction provided that the article is used in full and this copyright statement is reproduced. The author also grants a non-exclusive license to the University of Alberta to publish this document in full on the World Wide Web, and for the document to be published on mirrors on the World Wide Web. Any other usage is prohibited without the express permission of the authors. 